www.mdpi.com/journal/marinedrugs

Review

\title{
Phylogeny and Biogeography of Cyanobacteria and Their Produced Toxins
}

\section{Cristiana Moreira ${ }^{1,2}$, Vitor Vasconcelos ${ }^{1,2}$ and Agostinho Antunes ${ }^{1,2, *}$}

1 CIIMAR/CIMAR, Interdisciplinary Centre of Marine and Environmental Research, University of Porto, Rua dos Bragas, 289, Porto 4050-123, Portugal; E-Mails: cmoreira@ciimar.up.pt (C.M.); vmvascon@fc.up.pt (V.V.)

2 Biology Department, Faculty of Sciences, University of Porto, Rua do Campo Alegre, Porto 4169-007, Portugal

* Author to whom correspondence should be addressed; E-Mail: aantunes@ciimar.up.pt; Tel.: +351-223-401-813; Fax: +351-223-390-608.

Received: 16 July 2013; in revised form: 29 August 2013 / Accepted: 9 October 2013 / Published: 1 November 2013

\begin{abstract}
Phylogeny is an evolutionary reconstruction of the past relationships of DNA or protein sequences and it can further be used as a tool to assess population structuring, genetic diversity and biogeographic patterns. In the microbial world, the concept that everything is everywhere is widely accepted. However, it is much debated whether microbes are easily dispersed globally or whether they, like many macro-organisms, have historical biogeographies. Biogeography can be defined as the science that documents the spatial and temporal distribution of a given taxa in the environment at local, regional and continental scales. Speciation, extinction and dispersal are proposed to explain the generation of biogeographic patterns. Cyanobacteria are a diverse group of microorganisms that inhabit a wide range of ecological niches and are well known for their toxic secondary metabolite production. Knowledge of the evolution and dispersal of these microorganisms is still limited, and further research to understand such topics is imperative. Here, we provide a compilation of the most relevant information regarding these issues to better understand the present state of the art as a platform for future studies, and we highlight examples of both phylogenetic and biogeographic studies in non-symbiotic cyanobacteria and cyanotoxins.
\end{abstract}

Keywords: cyanobacteria; cyanotoxins; phylogeny and biogeography 


\section{Introduction}

\subsection{Cyanobacteria}

Cyanobacteria are a diverse group of microorganisms that have inhabited our planet for nearly 2.5 billion years [1]. Distributed in all types of ecological niches from the cold of Antarctica to the hot springs of Japan, New Zealand and Italy [2,3], they are characterized as being oxygenic photosynthetic prokaryotic microorganisms that possess chlorophyll $a[4,5]$. Cyanobacteria can pose serious risks to aquatic waterways and their users through the production of dense blooms in eutrophic systems leading to a decrease in water quality by the release of off-flavors, toxins, water discoloration and accumulation of surface scums [6]. With more than 1000 species and 150 genera [7] described so far, cyanobacteria are important fixers of atmospheric nitrogen in aquatic ecosystems. They produce oxygen as a by-product of this process [8] and have recently been proposed as a source of hydrogen for fuel production [9]. Cyanobacteria were initially classified as algae and consequently, grouped with plants according to the Botanical Code criteria [10]. Under this type of classification, morphological and physiological characteristics were used [11]. Later, cyanobacteria were reclassified by applying bacteriological criteria that uses morphological and reproductive characteristics; however, this is not supported by recent studies that use molecular data and phylogenetic analyses to revise cyanobacteria taxonomy [12-14]. Under the bacteriological code, cyanobacteria are classified into five subsections $[4,8]$. Subsection I (Order Chroococcales) is comprised of unicellular cyanobacteria with reproduction by binary fission or budding [4,8]. Subsection II (Order Pleurocapsales) is composed of unicellular cyanobacteria that reproduce by multiple fission releasing baeocytes [4,8]. Subsection III (Order Oscillatoriales) is composed of filamentous cyanobacteria, consisting solely of vegetative cells that can undergo binary fission only in a single plane and the formation of hormogonia [4,8]. In subsections IV (Order Nostocales) and V (Order Stigonematales), the cyanobacteria are also filamentous but differ from subsection III by the presence of differentiation cells known as heterocysts and akinetes and the formation of hormogonia [8]. The main difference between subsection IV and $\mathrm{V}$ is the form of vegetative reproduction. While in subsection IV the cyanobacteria species divide exclusively by binary fission in one plane (false branching), in subsection $\mathrm{V}$, they divide in more than one plane (true branching) [4,8].

\subsection{Cyanotoxins}

Cyanotoxins are a structurally diverse group of compounds that are produced by cyanobacteria. They are synthesized via a nonribosomal pathway and are a product of the secondary metabolism of cyanobacteria, and thus are not used in their primary metabolism [15,16]. Cyanotoxins occur in several genera of cyanobacteria and have the potential to impact aquatic ecosystems due to their toxic nature to both humans and aquatic animals as well as to wild and livestock animals [15]. Cyanotoxins, due to their toxic properties and mode of action, are classified as hepatotoxins (microcystins, nodularins and cylindrospermopsin), neurotoxins (anatoxin-a, saxitoxins) and dermal toxins (lyngbyatoxin, aplysiatoxin) [17]. Their production is not strain specific and can be found in a diverse range of species. Of all the cyanotoxins that have been described, the most widely studied are the hepatotoxins, microcystins and cylindrospermopsin. Microcystins have a worldwide distribution (found in all of the 
main continents) and are produced by a variety of cyanobacteria genera (e.g., Microcystis, Nostoc, Anabaena, Planktothrix). The relevance of studying them is reinforced by the well-known case of human mortality in a dialysis center in Brazil where 60 patients died of acute liver failure due to water contaminated with this toxin [18]. Cylindrospermopsin has been reported in four of the five continents (Africa is the exception) and in nine different species so far (Cylindrospermopsis raciborskii, Umezakia natans, Chrysosporum ovalisporum, Chrysosporum bergii, Raphidiopsis curvata, R. mediterranea, Aphanizomenon flos-aquae, Anabaena lapponica, Lyngbya wollei), clearly indicating that its production is not species-specific [19,20]. Cylindrospermopsin is known for the outbreak of hepatoenteritis that occurred in Palm Island, Australia in 1979 [21] where 148 people were affected and required hospitalization [22].

Biosynthesis of these compounds is performed by a family of multi-enzymatic complexes called nonribosomal peptide synthetases and polyketide synthases organized into repeated functional units known as modules $[23,24]$. Its transcription and translation is independent of the messenger RNA and are organized in the genome into gene clusters. These encode enzymes for the biosynthesis, regulation, and export of the toxins. The first biosynthetic pathway to be sequenced was that of microcystins [25], followed by the nodularin [26], cylindrospermopsin and saxitoxin gene clusters [27,28], and more recently, the anatoxin-a gene cluster [29].

\section{Molecular Studies in Cyanobacteria and Cyanotoxins}

Molecular studies in cyanobacteria and their produced cyanotoxins started in the early 1990s. They were based on the detection, identification, quantification, profiling, and assessing of genetic diversity and phylogenetics of a given species or taxa. Initially, detection, identification and enumeration of cyanobacteria were conducted with microscopic techniques, which are based on morphological criteria that ultimately require the presence of an experienced observer. Presence of cyanotoxins is nowadays evaluated by chemical methods such as High-Performance Liquid Chromatography (HPLC) and by immunological assays such as the Enzyme-Linked Immunosorbent Assay (ELISA), tests that not only detect the cyanotoxin but also quantify its concentration in a given sample. Newer and faster tools are necessary and in this sense, molecular methodologies have emerged. They have the advantages, in comparison with traditional methodologies, of being highly specific, sensitive and more rapid. Nowadays, molecular tools applied to cyanobacteria and cyanotoxin investigations are widely used and can be divided into Polymerase Chain Reaction (PCR) and non-PCR based methods. So far, several molecular methods have been developed, which have been applied to cyanobacteria and cyanotoxin research, which include PCR, multiplex-PCR, Restriction Fragment Length Polimorphism (RFLP), Amplified Fragment Length Polymorphism (AFLP), Multilocus Sequence Typing (MLST), Random Amplified Polymorphic DNA (RAPD), Denaturing Gradient Gel Electrophoresis (DGGE), Fluorescence in situ Hybridization (FISH), Real-time PCR (qPCR) and DNA microarrays. Their main applications include field investigations regarding the detection of cyanobacteria, toxicity evaluation and enumeration. For example, these methods allow, together with gene sequencing, the identification of cyanobacteria species from environmental samples, with the advantage of removing the time needed for laboratory growth of the cyanobacteria cultures. Other studies have relied on genetic data obtained through DNA sequencing of cyanobacteria and cyanotoxins genetic markers in isolated cyanobacterial 
species and have subjected them to phylogenetic analyses in order to assess their genetic diversity, population structure, and in some cases, the phylogeographic structure and biogeographic pattern of the isolates [30-32]. DNA sequencing has made a major contribution in terms of publicly available gene sequences from both cyanobacteria and cyanotoxins in worldwide databases, with more than 80 genomes from cyanobacterial species having been sequenced so far. Apart from these genomes, genetic databases are being increasingly filled with new partial and complete sequences of DNA, all due to the growing use of molecular methods in cyanobacteria and cyanotoxin research.

PCR analysis is the most frequent technique used in the in vitro amplification of a DNA sequence by target specific primers. Cyanobacteria detection can be achieved by amplifying several genetic markers that have been developed for that specific purpose. To date, several primers have been designed and published to amplify: (a) common cyanobacteria specific DNA regions and; (b) genera specific regions for Microcystis and C. raciborski [33,34].

Similarly, toxicological evaluation through molecular methodologies has been made possible for the cyanotoxins microcystins, nodularin, saxitoxin, cylindrospermopsin and anatoxin-a with the detection of the genes involved in the gene clusters encoding these biosynthetic compounds. All of these gene clusters have already been completely sequenced allowing the designing of primers for their detection by conventional PCR assays, such as the multiplex-PCR assay developed for microcystins [35], cylindrospermopsin [36] and the singleplex PCR assays for saxitoxin [27], nodularin [26], anatoxin-a [29], and more recently, the multiplex-PCR for both microcystin and cylindrospermopsin from both cultured and field samples [37]. Another outcome for these developed primers is their application in the qPCR technique allowing the quantification of both cyanobacteria and cyanotoxins directly from an environmental sample. This is a more sensitive method in comparison to conventional PCR with detection limits of 8.8 cell $/ \mathrm{mL}$ for Microcystis spp. and 258 cell $/ \mathrm{mL}$ for $C$. raciborskii from field samples [38,39]. It also allows for the evaluation of the proportion and abundance of a given species as well as the establishment of the proportion of toxic and non-toxic genotypes within a cyanobacterial bloom [40,41].

Other molecular methods have also been applied to cyanotoxin and cyanobacteria research based on PCR technology such as the RAPD, RFLP and DGGE. Altogether, these methods allow the profiling of cyanobacteria and cyanobacterial communities directly from the environment, where they have been commonly used (for further information on these methods please see the review from Saker et al. [42]).

Non-PCR based methods are based on DNA probes that have been applied to cyanobacteria and cyanotoxin detection, and more recently, quantification. Some studies regarding DNA microarrays have been applied to gene expression in cyanobacterial species [43] and in the genetic profiling of natural communities [44]. Studies with this type of technology in cyanotoxins are recent and have been only applied to validation in the detection of microcystin $(m c y E)$ and nodularin $(n d a F)$ cyanobacteria producers in both strains and environmental samples [45]. Finally, FISH studies have been useful in the identification of cyanobacteria in natural samples [46,47] and also of the cyanotoxin microcystin (mcyA) in the cyanobacterium M. aeruginosa [48]. 


\section{Phylogeny Studies in Cyanobacteria and Cyanotoxins}

\subsection{Genetic Markers}

In cyanobacteria and cyanotoxin phylogenetic inferences, several genetic markers have been used (Table 1), all with the distinct purposes of being able to determine the amount of genotypes and/or lineages of the gathered isolates in order to assess their genetic diversity in a given location, their population or phylogeographic structure (Table 1). Other purposes are to resolve taxonomic issues among genera or at the species level, as well as in the establishment of biogeographic patterns (Table 1). Similarly to other studies that have used these markers, they were applied either separately or in a concatenated system (multi-gene analysis) using up to seven genetic markers [49,50]. The choice of the best phylogenetic marker is somewhat controversial since in some studies, which used more than one genetic marker, the results are conflicting [51], while in others, there is a clear agreement between all the applied markers [52-54]. Other studies have recently used a multi-gene analysis rather than a single genetic marker [49,50]. In those, the accuracy and reliability of the phylogenetic inference is increased since more genetic information can be analyzed [55]. Nonetheless, this type of analysis has its disadvantages since it requires more PCR reactions and particularly, more DNA sequencing, which in turn, makes it more expensive than when using a single genetic marker. Examples of the application of genetic markers to cyanobacteria and cyanotoxin phylogeny and biogeography studies will be presented.

Table 1. List of the genetic markers used and their respective application in phylogeny and biogeography studies of cyanobacteria.

\begin{tabular}{|c|c|c|c|c|c|}
\hline Genetic marker & Taxonomy & Phylogenetic & Phylogeography & Evolution & Biogeography \\
\hline$P C-I G S$ & $\sqrt{ }$ & $\sqrt{ }$ & $\sqrt{ }$ & & $\sqrt{ }$ \\
\hline$f t s Z$ & & $\sqrt{ }$ & & & \\
\hline$g \ln A$ & & $\sqrt{ }$ & & & \\
\hline glt $X$ & & $\sqrt{ }$ & & & \\
\hline$g y r B$ & & $\sqrt{ }$ & & & \\
\hline$p g i$ & & $\sqrt{ }$ & & & \\
\hline $\operatorname{rec} A$ & & $\sqrt{ }$ & & & \\
\hline tpi & & $\sqrt{ }$ & & & \\
\hline 16S-23S ITS1-L & & $\sqrt{ }$ & $\sqrt{ }$ & & \\
\hline $16 S-23 S$ ITS1-S & & $\sqrt{ }$ & & & \\
\hline rров & $\sqrt{ }$ & & & & \\
\hline rpoCl & $\sqrt{ }$ & $\sqrt{ }$ & $\sqrt{ }$ & $\sqrt{ }$ & \\
\hline nifH & $\sqrt{ }$ & $\sqrt{ }$ & $\sqrt{ }$ & $\sqrt{ }$ & \\
\hline nifD & $\sqrt{ }$ & & & & \\
\hline $16 r R N A$ & $\sqrt{ }$ & $\sqrt{ }$ & $\sqrt{ }$ & $\sqrt{ }$ & $\sqrt{ }$ \\
\hline $16 S-23 S$ ITS & $\sqrt{ }$ & $\sqrt{ }$ & $\sqrt{ }$ & & $\sqrt{ }$ \\
\hline$r b c L X$ & $\sqrt{ }$ & & & & \\
\hline hetR & $\sqrt{ }$ & & & & \\
\hline$p s b A$ & & $\sqrt{ }$ & & & \\
\hline$r b c L$ & & $\sqrt{ }$ & & & \\
\hline$r b c S$ & & $\sqrt{ }$ & & & \\
\hline
\end{tabular}




\subsection{Taxonomic Studies}

Earlier in this review, we discussed the classification of cyanobacteria and established that the taxonomy was traditionally founded only on morphological characteristics. More recently, phylogenetic studies in cyanobacteria have applied genetic markers that aid in unraveling the association of related taxa through phylogenetic inferences. One of these examples is a study by Ishida et al. [56] where the $16 \mathrm{~S}$ rRNA was used to determine the phylogenetic position of eight genera of Oscillatoriales that had an obscure definition. The data from this work showed that the Oscillatoriales group is not monophyletic and is genotypically heterogeneous and, therefore, suggested that their current taxonomic position should be revised. Wilmotte et al. [57], by studying the taxonomy of the genus Oscillatoria, also found it to be genotypically heterogeneous. Previously, Giovannoni et al. [58] studied cyanobacteria taxonomy by using the 16S rRNA marker and discovered that subsections II, IV and V are phylogenetically coherent while subsections I and III appear intermixed in the phylogenetic tree. Applying another genetic marker (nifH), Zehr et al. [59] demonstrated that subsections I, II, IV and V formed coherent groups. Later, Valério et al. [60], using the 16S rRNA marker in a global phylogeny of the six cyanobacterial orders, showed that the Nostocales, Stigonematales and Pleurocapsales form monophyletic groups while the Chroococcales and Oscillatoriales are polyphyletic.

Based on the phylogenetic analysis of the 16S rRNA, Otsuka et al. [11] proposed the unification of five species of the genus Microcystis into a single species of M. aeruginosa under the Rules of the Bacteriological Code. The five morphospecies were M. aeruginosa, M. ichthyoblabe, M. novacekii, $M$. viridis and $M$. wesenbergii in which DNA-DNA hybridization and phylogenetic data both showed no clear distinction among strains with the first method having more than $70 \%$ homology. The data from this work proved that all five species belong to the same species of the cyanobacterium M. aeruginosa. Previously, Neilan et al. [33], in a study of the genus Microcystis, found that this species is well separated from the other unicellular genera such as Synechocystis, Synechococcus and the filamentous genus Nostoc based on the information given by the 16S rRNA alone. By studying other genera, Henson et al. [10] tried to determine if Nostoc and Anabaena are separate genera based on information provided by the molecular marker nifD, since previous studies showed that other markers proved unable to differentiate these. Their results show that the two genera formed separate clades and, therefore, should be maintained as separate. In a subsequent study, Henson et al. [12] tried to establish the mono or paraphyletic nature of subsections IV and V of the cyanobacteria Bacteriological Code. Applying the genetic marker nifD, which was established in a previous study [10] to be a good candidate marker in resolving the heterocystous cyanobacteria lineage, they attempted to establish whether or not these two subsections are divided. Phylogenetic analysis showed that the heterocystous is monophyletic. However, with the use of nifD, the subsections IV and V formed two clades appearing intermixed, suggesting that their phylogenetic relationships do not reflect its classification.

A subsequent study by Gugger et al. [53], aimed at explaining the taxonomic relationships between strains of Anabaena and Aphanizomenon, with the prior knowledge that both genera are closely related although morphologically distinguishable. By using three distinct genetic markers (16S rRNA, 16S-23S ITS and $r b c L X$ ), the answers they obtained were that both genera did not form distinct clusters and appeared intermixed in the phylogenetic trees with high similarity values obtained 
between studied strains. This study showed that the taxonomy of both genera may be incorrect although morphological data supported their separation. The same observation was also made by Valério et al. [60] when using only the 16S rRNA marker.

Aiming to evaluate whether true branching is a monophyletic characteristic in the Order Stigonematales, Gugger et al. [61] conducted a study using the 16S rRNA applied to 16 strains of this cyanobacterial Order, which revealed a polyphyletic nature of the branching type since the three types of true branching were intermixed in the phylogenetic tree. In another study, Rajaniemi et al. [62] evaluated four genera of cyanobacteria belonging to the Order Nostocales (Nostoc, Anabaena, Aphanizomenon and Trichormus) on the basis of their genetic relationships along with morphological criteria. Their results revealed that the taxonomic classification should be revised since the planktonic Anabaena/Aphanizomenon and benthic Anabaena were not monophyletic having appeared in the three studied genetic markers intermixed much like the Trichormus strains. In view of the retrieved data, morphological criteria established by both botanical and bacteriological codes were not in agreement with the obtained genetic relationships for these three genera [62]. In Anabaenopsis, two strains were studied-A. abijatae and A. elenkinii-since Anabaenopsis spp. can morphologically resemble planktonic Anabaena and Cylindrospermopsis species [52]. The strains were gathered from Kenya, Mexico and Uganda lakes and tested with two distinct genetic markers (16S rRNA and the PC-IGS). Both phylogenetically gave the same tree topology, but while the 16S rRNA gave a high similarity value $(97.5 \%)$, the PC-IGS gave a lower similarity value (93.6\%) [52]. This in terms of sequence divergence resulted in different answers meaning that while using the $16 \mathrm{~S}$ rRNA of the two strains indicated that they were the same species, the other genetic marker indicated that they were separated species. Alternatively, by using a multi-gene analysis consisting of four genetic markers (16S rRNA, het $\mathrm{R}$, nifH and rpoC1), Thomazeau et al. [63] studied strains from the Sub-Saharan region in order to determine their contribution to the phylogeny of cyanobacteria. They found in their study the monophyly of Synechococcales, Chroococcales, Oscillatoriales (except the Phormidium-like lineage) and the Nostocales including the Phormidium-like lineage and the polyphyly of Pseudanabaenales [63]. Taxonomic revisions and erection of new taxa has become available in three recent studies from Komárek [13], Komarék \& Mareš [14] and Zapomělová et al. [64]. All refer to the taxonomic revision of freshwater planktonic heterocystous cyanobacteria and the nostocacean genera should be based on the phylogenetic analysis of the $16 \mathrm{~S}$ rRNA gene sequences, providing evidence that molecular methods are an important tool in the phylogenetic assignments of related taxa. Another work by Zapomělová et al. [64] describes how molecular methods can influence the erection of new taxa through gene sequencing of the 16S rRNA and phylogenetic analysis of the related taxa. In this last study, it was confirmed that Anabaena bergii and Aphanizomenon ovalisporum were transferred to the new Chrysosporum bergii and Chrysosporum ovalisporum, respectively. Also, in this work, the reclassification of Anabaena tenericaulis as Dolichospermum tenericaule was proposed.

\subsection{Phylogenetic Studies}

Determining the genetic diversity and population structure are the main aims in this type of study. In general, the research is focused on the collection of isolates of a certain cyanobacterial species and phylogenetic group to evaluate the population structure within a given lake, region or country, as well 
as to establish the genetic diversity (number of genotypes or lineages) of the isolates within the studied area. These studies also rely on the application of the genetic information of the isolated strains and compare them to their morphological characteristics. One of the most studied cyanobacteria genera is Microcystis. A study by Bittencourt-Oliveira et al. [30] is particularly relevant, where the genetic diversity of $M$. aeruginosa strains from a Brazilian reservoir was assessed and compared with their morphological characteristics. The study resulted in the formation of eight distinct genotypes and five lineages, which demonstrated the high degree of heterogeneity that this species carries in Brazilian waters based on the information of the phycocyanin intergenic spacer. Moreover, the results indicated that there was no correlation between morphotypes and genotypes with one genotype having more than one morphotype [30]. These results are in concordance with a subsequent study by Neilan et al. [65], where the genetic diversity for this genus was first established as heterogeneous since it formed several genetic lineages in the phylogenetic tree of the RFLP profiles. Other studies on Microcystis used other genetic markers and were carried out in other locations. These include the USA [66], Kenya and Uganda [54], Russia [67], Tunisia [68,69] and Japan [70,71]. In all, a high level of genetic diversity was observed with a high number of genotypes having been found. The heterogeneity of this genus is so well established that Wilson et al. [66] determined that the genetic variation between and among lakes is high with 53 out of 67 isolates shown to be genetically distinct. Other work with Microcystis relied on the separation of toxic from non-toxic forms assuming that phylogeny can be used as a tool to allow this separation without reverting to the traditional techniques that determine the toxicity of the isolates or strains. Some studies were conducted in this area such as those of Otsuka et al. [72] and Tanabe et al. [49]. The differences are that they first used a single genetic marker (16S-23S rRNA ITS) and they second used seven housekeeping genes targeting specifically M. aeruginosa in a MLST approach. In both studies, a clear separation of toxic from non-toxic strains of Microcystis was obtained, suggesting that both assays could be used in the assessment of a given strain or isolate as toxic or non-toxic for microcystins. Studies such as these have also been conducted in other cyanobacterium species such as Anabaena circinalis where the 16S rRNA marker was able to separate neurotoxic strains from non-neurotoxic strains [73]. In contrast, for toxic and non-toxic C. raciborskii cylindrospermopsin producing strains, Stucken et al. [74] demonstrated in a phylogenetic study that there was no relation between the phylogeny of the two genetic markers used (16S rRNA and 16S-23S ITS) and the presence of toxicity.

Phylogenetic studies in other cyanobacterium genera have also been carried out. Their main objective was to establish a correlation between genotypic data and phenotypes. Genera from the Order Nostocales have been also well studied such as Nostoc [75] and Aphanizomenon [76]. In the study of Svenning et al. [75], they aimed to demonstrate whether the 16S rRNA was able to distinguish symbiotic strains of this genus from free-living strains, and revealed that both types appeared intermixed in the phylogenetic tree. Using the genus Aphanizomenon, Wu et al. [76] assessed the morphological data and compared them with the genotypic data in Chinese freshwaters in order to determine the genetic diversity within this genus. Their data revealed that morphologically three strains of Aphanizomenon: Aph. flos-aquae, Aph. issatschenkoi and Aph. gracile were identified. The genotypic data was based on the information of three genetic markers that were analyzed separately and in a multi-gene analysis comprehending the $16 \mathrm{~S}$ rRNA, $r b c \mathrm{LX}$ and $c p c B A$-IGS. The tree topologies for each gene were different but when using a concatenated system, the three Aphanizomenon strains 
that were identified grouped separately, something that was not observed when using either of the markers individually. Also, in an earlier study, Barker et al. [77] found that the genetic population of Nodularia in the Baltic Sea is heterogeneous with more than one genotype having been found. In C. raciborskii, a low genetic variability was observed when comparing isolates from several locations in Tunisia that appeared in a unique cluster with the use of the rpoCl marker [69,78].

\subsection{Evolutionary Studies}

In the Tree of Life, cyanobacteria are represented in the Bacteria group. In a study where the evolutionary relationships among cyanobacteria were evaluated, Giovannoni et al. [58] revealed that the deepest branches in the cyanobacterial phylogenetic tree were from Gloeobacter violaceus and two strains of the genus Pseudanabaena. Also, the unicellular and nonheterocystous filamentous cyanobacteria of subsection III appeared intermixed throughout the $16 \mathrm{~S}$ rRNA phylogenetic tree suggesting that they might have multiple evolutionary origins [58]. Their data also suggested that heterocystous cyanobacteria may have diverged later in the cyanobacteria lineage. Also, Zehr et al. [59], based on the similarities of both nifH and $16 \mathrm{~S}$ rRNA, arrived at the same conclusion. They have also proposed that the nif $\mathrm{H}$ genes responsible for nitrogenase genes were not obtained through horizontal gene transfer but by vertical transmission from an ancient ancestor. In another study, Neilan et al. [33] proposed the late divergence of the Microcystis genus due to high sequence conservation observed in the 16S rRNA. Turner et al. [79], in an in-depth evolutionary study of the cyanobacteria lineage and the 16S rRNA marker, determined that the most ancient descent of cyanobacteria is in fact Gloeobacter violaceus. They also confirmed the work of Nelissen et al. [80] that within cyanobacterial divergence the early origin of plastids was only preceded by two cyanobacterial genera, Gloeobacter and Pseudanabaena [80]. Evolutionary studies regarding the origin of cyanobacteria genera or species are scarce. Moreira et al. (unpublished data) conducted a study on the cyanobacterium M. aeruginosa and established that this species may have originated from the African continent. Studies such as these are scarce, but are nonetheless imperative.

The only work regarding the evolution of cyanotoxins is Rantala et al. [81] which established the early evolution of the cyanotoxin microcystins in contrast to the non-toxic species, and that these appeared as a result of the loss of ability to produce the toxin. Also in their work, they found that the nodularin toxin derived from microcystins. Evolution of other cyanotoxins is yet to be elucidated.

\subsection{Phylogeographic Studies}

Phylogeography allows the establishment of phylogenetic relationships within and among species from distinct geographic locations with the purpose of determining the presence or absence of spatial patterns. Studies based on the phylogeography of cyanobacteria genera or species are scarce and are based on the phylogenetic comparison of strains from diverse geographic origins. Some genera and species have been studied, namely Aphanizomenon, C. raciborskii and M. aeruginosa. Barker et al. [77] used the PC-IGS genetic marker to compare the population genetics of the Aphanizomenon in the Baltic Sea and in two North American lakes. Their data revealed that only a single genotype was found in the Baltic Sea Aphanizomenon colonies and that these are closer to the North American colonies. 
They also found that the two North American lakes analyzed had a higher genetic variation than the one observed in the Baltic Sea.

C. raciborskii is a cyanobacterium species that has received particular attention in regards to its phylogeographic structure due to its well-known invasive nature [82]. The five studies published to date all share the view that this species has a well-established phylogeographic structure. Dyble et al. [51] was the first to compare C. raciborskii strains from distinct geographic locations (Europe, Australia, America) by using two distinct genetic markers (nifH and $c p c B A$-IGS). Both gave a different clustering with nifH marker forming three separate clusters: Europe, Australia and America while the $c p c B A$-IGS marker formed two distinct clusters: Europe/Australia and America. Altogether, they were able to only differentiate the American isolates. In a subsequent study, Neilan et al. [83] published the phylogeography of this cyanobacterium species based on information from the $16 \mathrm{~S}$ rRNA and cyanobacteria HIP1 PCR profiles. Although strains from the same continents were analyzed, similarly to the work of Dyble et al. [51], they established that the 16S rRNA marker in contrast to the HIP1 PCR profiles does not allow a good differentiation of the strains, especially at the species level. Nevertheless, they found two major groups being defined by the HIP1 PCR profiles that distinctly separate the American strains from the European and Australian strains. Their data also showed that in the Europe/Australia group, there was a high degree of genetic divergence. Later, Gugger et al. [84] increased the number of sampled continents for this species to four (Europe, Africa, Australia and America). Their conclusions based on information from the 16S-23S ITS marker showed that three main clusters existed: Europe, America and Australia/Africa. Haande et al. [85] also published a work using strains from the same four continents but utilizing three genetic markers (16S-23S ITS-L, nifH and PC-IGS) in a multi-gene analysis. The conclusions were the presence of three distinct clusters, with the strains of Africa being closer to the Australian strains, the American strains being more divergent and the European strains being closer to the Australian/African group [85]. In a more recent study, Moreira et al. [31] analyzed strains from all the main continents with a concatenated system of four genetic markers (16S rRNA, 16S-23S ITS-L, 16S-23S ITS-S rRNA and rpoC1) and identified three main clusters at a global scale: Europe, Australia/Asia and America/Africa.

M. aeruginosa is another cyanobacterium species that has been studied at a phylogeographical level. Neilan et al. [33] were the first to establish that the genera have no phylogeographic structure. By using the 16S rRNA marker, they found a high degree of genetic similarity (>91\%) among strains from distinct geographic locations. Afterwards, Bittencourt-Oliveira et al. [30] applied the genetic marker $c p c B A$-IGS in their isolated strains from Brazil and compared them to strains from other geographic locations, namely Europe, North America and Japan, and found that these all appear to not form any distinct clustering among them and between the Brazilian strains. In a similar study, using two distinct genetic markers (PC-IGS and 16S-23S ITS), Haande et al. [54] analyzed the strains isolated from Uganda and Kenya with others from distinct geographic locations and found also that there is no well-defined phylogeographic structure, with the clusters consisting of strains from all around the world. Recently, by applying M. aeruginosa from all the main continents and through sequencing of DGGE bands of the 16S-23S ITS marker, van Gremberghe et al. [86] showed that the species carries in fact no phylogeographic structure and concluded that, at a biogeographic level, the species is considered to be cosmopolitan. 


\section{Biogeography Studies in Cyanobacteria and Cyanotoxins}

Biogeography is a multidisciplinary science that aims to study living things in space and time [87]. Although the science has long focused on the distribution of animals and plants, microorganisms have only recently been debated. This is because microorganisms are easily dispersed globally, raising the question of whether they, like many macro-organisms, have historical biogeographies. Prokaryotic biogeography has been previously defined as the science that documents the spatial distribution of prokaryotic taxa in the environment at local, regional and continental scales [88]. Phenomena such as speciation, dispersal and extinction are proposed to explain the generation of biogeographic patterns [88]. Of all kinds of dispersal, passive dispersal is the most common to occur in cyanobacteria [89]. Vectors of passive dispersal for cyanobacteria include water bodies, fish, water birds, winds, airplanes, humans and scientific activities [89]. Biogeography studies involving cyanobacteria are generally based on the discovery of new genera or species in new environments. One of the studies published to date documenting the presence of cyanobacteria in extreme environments is that of Bahl et al. [32] in hot and cold desert cyanobacteria. Others such as the work of Strunecký et al. [90] describe the presence of Phormidium autumnale from ancient times in the Antarctic area, and others like Mazard et al. [91] and Ahlgren et al. [92] are based on the biogeography of the marine Synechococus, in North and South Atlantic gyres and Pacific Ocean waters, respectively. Regarding cyanotoxin biogeography, a single study by Moreira et al. [93] established that for M. aeruginosa microcystin-producing strains, the Asian continent appeared separated from the other continental groups and that those strains are closely related to European and North American strains.

The methods for biogeographic study in cyanobacteria and cyanotoxins are based on the identification and subsequent phylogenetic analyses of the isolates or environmental samples using predetermined genetic markers to establish their genetic diversity and geographical interaction. Examples include the studies of Taton et al. [94] and Ionescu et al. [95]. Both report the presence of cyanobacteria in extreme environments such as hot springs in Jordan [95] and in the East Antarctic lakes [94]. Other works report the presence of cyanobacteria species or genera in hot and cold deserts [32], namely in the public hot springs of Saudi Arabia [96], and also the presence of the cyanotoxin microcystin-LR in the cold Antarctic environment [97] and microcystin-LR and -RR in Saudi Arabian hot springs [96]. Reports of the presence of cyanobacteria in Artic and alpine habitats have also been described [98,99] as well as in hypersaline environments [100]. Besides the information on the presence of cyanobacteria and cyanotoxins in extreme environments, other studies describe how geography can influence cyanobacteria distribution at local or global scales. This is the case for Nodularia strains that were separately analyzed at a local scale (Baltic Sea) and at a global scale [101,102]. In the first study, a population structure was determined for the Nodularia strains isolated from nine stations in the Baltic Sea, which revealed the presence of two distinct genotypes that were not spatially equally distributed. In the second study, a worldwide comparison of Nodularia strains was conducted. In the work of Bolch et al. [101], through PCR-RFLP, RAPD and PC-IGS DNA sequencing, clustering revealed that the Australian Nodularia strains were distinct from the other locations worldwide (Europe and North America) and that between these are distinct populations of Nodularia. 
Studies highlighting the impact of geography on cyanobacteria distribution are scarce but relevant for prokaryotic biogeography. One of these is the work of Papke et al. [3] where Synechococcus was screened in hot spring cyanobacterial mats from North America, Japan, New Zealand and Italy. From the data collected, it was observed that geographical isolation is the main reason why cyanobacteria diverged in these types of ecosystems since the same genotypes were found within and between countries. The data obtained from this study suggests that the central dogma "everything is everywhere but nature selects" is wrong since it denotes that there are no barriers for physical dispersion, where in contrast, this study shows that microorganisms are influenced by dispersal mechanisms. Other studies gave new insights in cyanobacteria biogeography, namely the works of Taton et al. [94] and Ionescu et al. [95]. In the study of Taton et al. [94] regarding the biogeography in the East Antarctic lakes, several cyanobacteria species were found to be endemic to those lakes while others were found to exist in other parts of the world, revealing the species' capability of dispersal. In a similar study, Ionescu et al. [95] studied the cyanobacteria diversity of an isolated Jordan hot spring and found organisms equivalent to others found in thermal environments around the world, as well as endemic species. Since this particular ecosystem is completely isolated, the only possible explanation for this biogeographical finding is based on two previous biogeography theories: on one hand, the central dogma "everything is everywhere but the environment selects" could be true or on the other hand, the presence of chemical and physical barriers prevents the gene flow, making the organisms diverge from their ancestors since local speciation was found to occur [95].

Other more restricted studies about cyanobacteria biogeography involve the study of the worldwide distribution of a given cyanobacteria species. Garcia-Pichel et al. [103] found that the species Microcoleus chthonoplastes is a cosmopolitan species due to the low genetic diversity of the $16 \mathrm{~S}$ rRNA sequences of the worldwide isolates. More recently, van Gremberghe et al. [86], also in a similar study, demonstrated the lack of phylogeographic structure in M. aeruginosa on a worldwide scale revealing that the species may have in fact a truly cosmopolitan distribution. Another study by Moreira et al. [31] about the worldwide distribution of C. raciborskii indicated that the European strains were probably colonized by strains from the Asian or Australian continents indicating the capability of dispersal that this species carries. Several hypotheses of dispersal have been proposed for the invasive C. raciborskii [82]. Initially, Padisák [82] proposed, based on documented reports, that the species had a first radiation center in the African continent and then dispersed to Indonesia and Central America and a second radiation center in Australia and that dispersion from there had then likely occurred by two routes: (1) an oceanic route to North and South America through birds or by unintentional human introduction; and (2) a continental route to Central Asia reaching the European continent also through birds and by river courses. Gugger et al. [84] later proposed a second hypothesis on the proliferation of this species suggesting that its recent invasion was not a spread either from Africa or Australia, but instead from warm refuge areas on each continent. The expansion to more temperate environments was proposed as follows: during the multiple glaciations and climatic changes of the Pleistocene, the species survived and the recent temperature elevation allowed the colonization of more areas. Later Haande et al. [85] suggested, based on the discrepancies in phylogeny, morphology and toxicology data that the spread of this species would have been rather through radiation within continents than the recent exchange between continents. 
The studies presented so far report the distribution of cyanobacteria genera or species at a spatial level, but as stated initially, biogeography is the science that documents the distribution of a given taxa on spatial and temporal scales. For the latter, there is to date only one study from Bahl et al. [32] where they analyzed the biogeography of Chroococcidiopsis both at the temporal and spatial level in hot and cold deserts on a worldwide scale. Data from this work showed that the population is homogeneous through time and also, that the exchange between hot and cold deserts is a rare event. By using a calibrated microfossil, this study allowed a temporal scale to be added and also revealed that the central dogma that everything is everywhere is not correct since the same phylotype does not exist in both types of deserts, despite having a common ancestor. Also, the study reports that dispersal is not contemporary but ancient, and that it does not occur in the present day.

In light of the current knowledge, searching for cyanobacteria and studying their biogeography on a worldwide scale is the next step not only at the spatial level but also at the temporal level since it becomes imperative to establish whether or not microorganisms have patterns across space and time much like eukaryotes. Cyanobacteria biogeography is relatively recent and its incursion should not only be in extreme environments or distant regions such as the Polar Regions. Although relevant, the notion remains whether or not these microorganisms have, at a species level, a geographical segregation or as proved earlier, a cosmopolitan nature.

\section{Conclusions}

A compilation of the numerous studies in the field of phylogeny and biogeography for the cyanobacteria group and their produced cyanotoxins was the main goal of this review. The presented studies allow us to conclude that cyanobacteria phylogeny research has been restricted essentially to phylogenetic studies where the establishment of the genetic diversity of the isolates is the primary objective. Followed by taxonomic studies, the question of morphological classification of the genera or species was introduced into discussion from which the main conclusion is that the current taxonomic position of some genera should be revised. Evolutionary studies are poorly developed in cyanobacteria since most studies are about the origin and positioning of cyanobacteria within the Bacteria group. Though relevant, they pose the question of when the several cyanobacteria lineages arose in living history. Phylogeographic studies provided some light regarding the spatial patterning of the cyanobacteria genera and species around the globe. Though ubiquitous, some species of cyanobacteria were shown to have a spatial distribution in some of the studies, while in others, they were proven to be cosmopolitan. In this sense, biogeography is still in its infancy in cyanobacteria and cyanotoxin research. Though associated with the phylogeographic structure, this research aims to explain how this structure has come about in both time and space. Still limited to extreme areas of the world, recent publications have proven that much remains to be known about the occurrence and spread of cyanobacteria species as well as their related toxins, and to firmly establish if prokaryotic organisms are easily dispersed or have historical biogeographic patterns much like eukaryotes.

\section{Acknowledgments}

This research was funded by the PTDC/AAC-AMB/104983/2008 (FCOMP-01-0124-FEDER-008610), PTDC/AAC-CLI/116122/2009 (FCOMP-01-0124-FEDER-014029) and PEst-C/MAR/LA0015/2013 
projects from Fundação para a Ciência e Tecnologia (FCT), and by the $\mathrm{PhD}$ fellowship to Cristiana Moreira (Ref. SFRH/BD/47164/2008) from FCT.

\section{Conflicts of Interest}

The authors declare no conflict of interest.

\section{References}

1. Summons, R.E.; Jahnke, L.L.; Hope, J.M.; Logan, G.A. 2-Methylhopanoids as biomarkers for cyanobacterial oxygenic photosynthesis. Nature 1999, 400, 554-557.

2. Jungblut, A.D.; Hawes, I.; Mountfort, D.; Hitzfeld, B.; Dietrich, D.R.; Burns, B.P.; Neilan, B.A. Diversity within cyanobacterial mat communities in variable salinity meltwater ponds of McMurdo Ice Shelf, Antarctica. Environ. Microbiol. 2005, 7, 519-529.

3. Papke, R.T.; Ramsing, N.B.; Bateson, M.M.; Ward, D.M. Geographic isolation in hot spring cyanobacteria. Environ. Microbiol. 2003, 5, 650-659.

4. Castenholz, R.W. Phylum BX. Cyanobacteria. Oxygenic Photosynthetic Bacteria; Springer-Verlag: New York, NY, USA, 2001; pp. 473-599.

5. Woese, C.R. Bacterial evolution. Microbiol. Rev. 1987, 51, 221-271.

6. Ibelings, B.W.; Chorus, I. Accumulation of cyanobacterial toxins in freshwater "seafood" and its consequences for public health, a review. Environ. Pollut. 2007, 150, 177-192.

7. Rippka, R.; Deruelles, J.; Waterbury, J.B.; Herdman, M.; Stanier, R.Y. Generic assignments, strain histories and properties of pure cultures of cyanobacteria. J. Gen. Microbiol. 1979, 111, $1-61$.

8. Berman-Franka, I.; Lundgrenb, P.; Falkowski, P. Nitrogen fixation and photosynthetic oxygen evolution in cyanobacteria. Res. Microbiol. 2003, 154, 157-164.

9. Tiwari, A.; Pandey, A. Cyanobacterial hydrogen production-A step towards clean environment. Int. J. Hydrog. Energy 2011, 37, 139-150.

10. Henson, B.J.; Watson, L.E.; Barnum, S.R. Molecular differentiation of the heterocystous cyanobacteria, Nostoc and Anabaena, based on complete NifD sequences. Curr. Microbiol. 2002, $45,161-164$.

11. Otsuka, S.; Suda, S.; Shibata, S.; Oyaizu, H.; Matsumoto, S.; Watanabe, M.M. A proposal for the unification of five species of the cyanobacterial genus Microcystis Kützing ex Lemmermann 1907 under the rules of the Bacteriological Code. Int. J. Syst. Evol. Microbiol. 2001, 51, 873-879.

12. Henson, B.J.; Hesselbrock, S.M.; Watson, L.E.; Barnum, S.R. Molecular phylogeny of the heterocystous cyanobacteria (susections IV and V) based on nifD. Int. J. Syst. Evol. Microbiol. 2004, 54, 493-497.

13. Komarék, J. Modern taxonomic revision of planktic nostocacean cyanobacteria: A short review of genera. Hydrobiologia 2010, 639, 231-243.

14. Komarék, J.; Mareš, J. An update to modern taxonomy (2011) of freshwater planktic heterocystous cyanobacteria. Hydrobiologia 2012, 698, 327-351.

15. Carmichael, W. Cyanobacteria secondary metabolites - the cyanotoxins. J. Appl. Bacteriol. 1992, 72, 445-459. 
16. Pearson, L.A.; Moffitt, M.C.; Ginn, H.P.; Neilan, B.A. The molecular genetics and regulation of cyanobacterial peptide hepatotoxin biosynthesis. Crit. Rev. Toxicol. 2008, 38, 847-856.

17. Carmichael, W.W.; Liu, R. Cyanobacteria toxins in the Salton Sea. Saline Syst. 2006, 2, 1-13.

18. Jochimsen, E.M.; Carmichael, W.W.; An, J.S.; Cardo, D.M.; Cookson, S.T.; Holmes, C.E.; Antunes, M.B.; de Melo Filho, D.A.; Lyra, T.M.; Barreto, V.S.; et al. Liver failure and death after exposure to microcystins at a hemodialysis center in Brazil. N. Engl. J. Med. 1998, 338, 873-878.

19. Moreira, C.; Azevedo, J.; Antunes, A.; Vasconcelos, V. Cylindrospermopsin: Occurrence, methods of detection and toxicology. J. Appl. Microbiol. 2012, 114, 605-620.

20. Glenn, B.; McGregor, G.B.; Sendall, B.C.; Hunt, L.T.; Eaglesham, G.K. Report of the cyanotoxins cylindrospermopsin and deoxy-cylindrospermopsin from Raphidiopsis mediterranea Skuja (Cyanobacteria/Nostocales). Harmful Algae 2011, 10, 402-410.

21. Hawkins, P.R.; Runnegar, M.T.C.; Jackson, A.R.B.; Falconer, I.R. Severe hepatotoxicity caused by the tropical cyanobacterium (blue-green alga) Cylindrospermopsis raciborskii (Woloszynska) Seenaya and Subba Raju isolated form a domestic supply reservoir. Appl. Environ. Microbiol. 1985, 50, 1292-1295.

22. Byth, S. Palm island mystery disease. Med. J. Aust. 1980, 2, 40-42.

23. Cane, D.E.; Walsh, C.T. The parallel and convergent universes of polyketide synthases and nonribosomal peptide synthetases. Chem. Biol. 1999, 6, R319-R325.

24. Dittmann, E.; Neilan, B.A.; Borner, T. Molecular biology of peptide and polyketide biosynthesis in cyanobacteria. Appl. Microbiol. Biotechnol. 2001, 57, 467-473.

25. Tillett, D.; Dittmann, E.; Erhard, M.; von Döhren, H.; Börner, T.; Neilan, B.A. Structural organization of microcystin biosynthesis in Microcystis aeruginosa PCC 7806: An integrated peptidepolyketide synthetase system. Chem. Biol. 2000, 7, 753-764.

26. Moffitt, M.C.; Neilan, B.A. Characterization of the nodularin synthetase gene cluster and proposed theory of the evolution of cyanobacterial hepatotoxins. Appl. Environ. Microbiol. 2004, $70,6353-6362$.

27. Mihali, T.K.; Kellmann, R.; Muenchhoff, J.; Barrow, K.D.; Neilan, B.A. Characterization of the gene cluster responsible for cylindrospermopsin biosynthesis. Appl. Environ. Microbiol. 2008, 74, 716-722.

28. Kellmann, R.; Mihali, T.K.; Neilan, B.A. Identification of a saxitoxin biosynthesis gene with a history of frequent horizontal gene transfer. J. Mol. Evol. 2008, 67, 526-538.

29. Rantala-Ylinen, A.; Känä, S.; Wang, H.; Rouhiainen, L.; Wahlsten, M.; Rizzi, E.; Berg, K.; Gugger, M.; Sivonen, K. Anatoxin - a synthetase gene cluster of the cyanobacterium Anabaena sp. strain 37 and molecular methods to detect potential producers. Appl. Environ. Microbiol. 2011, 77, 7271-7278.

30. Bittencourt-Oliveira, M.C.; Oliveira, M.C.; Bolch, C.J.S. Genetic variability of Brazilian strains of the Microcystis aeruginosa complex (Cyanobacteria/Cyanophyceae) using the phycocyanin intergenic spacer and flanking regions (cpcBA). J. Phycol. 2001, 37, 810-818.

31. Moreira, C.; Fathalli, A.; Vasconcelos, V.; Antunes, A. Genetic diversity and structure of the invasive toxic cyanobacterium Cylindrospermopsis raciborskii. Curr. Microbiol. 2011, 62, 1590-1595. 
32. Bahl, J.; Lau, M.C.Y.; Smith, G.J.D.; Vijaykrishna, D.; Cary, S.C.; Lacap, D.C.; Lee, C.K.; Papke, T.; Warren-Rhodes, K.A.; Wong, F.K.Y.; et al. Ancient origins determine global biogeography of hot and cold desert cyanobacteria. Nat. Commun. 2011, 2, 163.

33. Neilan, B.A.; Jacobs, D.; del Dot, T.; Blackall, L.L.; Hawkins, P.R.; Cox, P.T.; Goodman, A.E. rRNA sequences and evolutionary relationships among toxic and nontoxic cyanobacteria of the genus Microcystis. Int. J. Syst. Bacteriol. 1997, 47, 693-697.

34. Wilson, K.M.; Schembri, M.A.; Baker, P.D.; Saint, C.P. Molecular characterization of the toxic cyanobacterium Cylindrospermopsis raciborskii and design of a species-specific PCR. Appl. Environ. Microbiol. 2000, 66, 332-338.

35. Ouahid, Y.; Pérez-Silva, G.; del Campo, F.F. Identification of potentially toxic environmental Microcystis by individual and multiple PCR amplification of specific microcystin synthetase gene regions. Environ. Toxicol. 2005, 20, 235-242.

36. Fergusson, K.M.; Saint, P.C. Multiplex PCR assay for Cylindrospermopsis raciborskii and cylindrospermopsin-producing cyanobacteria. Environ. Toxicol. 2003, 18, 120-125.

37. Barón-Sola, A.; Ouahid, Y.; del Campo, F.F. Detection of potentially producing cylindrospermopsin and microcystin strains in mixed populations of cyanobacteria by simultaneous amplification of cylindrospermopsin and microcystin gene regions. Ecotoxicol. Environ. Saf. 2012, 75, 102-108.

38. Furukawa, K.; Noda, N.; Tsuneda, S.; Saito, T.; Itayama, T.; Inamori, Y. Highly sensitive real-time PCR assay for quantification of toxic cyanobacteria based on microcystin synthetase A gene. J. Biosci. Bioeng. 2006, 102, 90-96.

39. Moreira, C.; Martins, A.; Azevedo, J.; Freitas, M.; Regueiras, A.; Vale, M.; Antunes, A.; Vasconcelos, V. Application of real-time PCR in the assessment of the toxic cyanobacterium Cylindrospermopsis raciborskii abundance and toxicological potential. Appl. Microbiol. Biotechnol. 2011, 92, 189-197.

40. Kurmayer, R.; Kutzenberger, T. Application of real-time PCR for quantification of microcystin genotypes in a population of the toxic cyanobacterium Microcystis sp. Appl. Environ. Microbiol. 2003, 69, 6723-6730.

41. Rinta-Kanto, J.M.; Ouellette, A.J.A.; Boyer, G.L.; Twiss, M.R.; Bridgeman, T.B.; Wilhelm, S.W. Quantification of toxic Microcystis spp during the 2003 and 2004 blooms in western lake Erie using quantitative real-time PCR. Environ. Sci. Technol. 2005, 39, 4198-4205.

42. Saker, M.; Moreira, C.; Martins, J.; Neilan, B.; Vasconcelos, V.M. DNA profiling of complex bacterial populations: Toxic cyanobacterial blooms. Appl. Microbiol. Biotechnol. 2009, 85, 237-252.

43. Li, H.; Singh, A.K.; McIntyre, L.M.; Sherman, L.A. Differential gene expression in response to hydrogen peroxide and the putative PerR regulon of Synechocystis sp. strain PCC 6803. J. Bacteriol. 2004, 186, 3331-3345.

44. Rudi, K.; Skulberg, O.M.; Skulberg, R.; Jakobsen, K.S. Application of sequence-specific labeled 16S rRNA gene oligonucleotide probes for genetic profiling of cyanobacterial abundance and diversity by array hybridization. Appl. Environ. Microbiol. 2000, 66, 4004-4011.

45. Rantala, A.; Rizzi, E.; Castiglioni, B.; de Bellis, G.; Sivonen, K. Identification of hepatotoxin-producing cyanobacteria by DNA-chip. Environ. Microbiol. 2008, 10, 653-664. 
46. Schönhuber, W.; Zarda, B.; Eix, S.; Rippka, R.; Herdman, M.; Ludwig, W.; Amann, R. In situ identification of cyanobacteria with horseradish peroxidase-labeled, rRNA-targeted oligonucleotide probes. Appl. Environ. Microbiol. 1999, 65, 1259-1267.

47. Worden, A.Z.; Chisholm, S.W.; Binder, B.J. In situ hybridization of Prochlorococcus and Synechococcus (Marine Cyanobacteria) spp. with rRNA-targeted peptide nucleic acid probes. Appl. Environ. Microbiol. 2000, 66, 284-289.

48. Metcalf, J.S.; Reilly, M.; Young, F.M.; Codd, G.A. Localization of microcystin synthetase genes in colonies of the cyanobacterium Microcystis using fluorescence in situ hybridization. J. Phycol. 2009, 45, 1400-1404.

49. Tanabe, Y.; Kasai, F.; Watanabe, M.M. Multilocus sequence typing reveals high genetic diversity and clonal population structure of the toxic cyanobacterium Microcystis aeruginosa. Microbiology 2007, 153, 3695-3703.

50. Wu, Z.; Shi, J.; Xiao, P.; Liu, Y.; Li, R. Phylogenetic analysis of two cyanobacterial genera Cylindrospermopsis and Raphidiopsis based on multi-gene sequences. Harmful Algae 2011, 10, 419-425.

51. Dyble, J.; Paerl, H.W.; Neilan, B.A. Genetic characterization of Cylindrospermopsis raciborskii (Cyanobacteria) isolated from diverse geographic origins based on nif $\mathrm{H}$ and $c p c \mathrm{BA}-\mathrm{IGS}$ nucleotide sequence analysis. Appl. Environ. Microbiol. 2002, 68, 2567-2571.

52. Ballot, A.; Dadheech, P.K.; Haande, S.; Krienitz, L. Morphological and phylogenetic analysis of Anabaenopsis abijatae and Anabaenopsis elenkinii (Nostocales, Cyanobacteria) from tropical inland water bodies. Microb. Ecol. 2008, 55, 608-618.

53. Gugger, M.; Lyra, C.; Henriksen, P.; Couté, A.; Humbert, J.F.; Sivonen, K. Phylogenetic comparison of the cyanobacterial genera Anabaena and Aphanizomenon. Int. J. Syst. Evol. Microbiol. 2002, 52, 1867-1880.

54. Haande, S.; Ballot, A.; Rohrlack, T.; Fastner, J.; Wiedner, C.; Edvardsen, B. Diversity of Microcystis aeruginosa strains (Chroococcales, cyanobacteria) from East-African water bodies. Arch. Microbiol. 2007, 188, 15-25.

55. Gadagkar, S.R.; Rosenberg, M.S.; Kumar, S. Inferring species phylogenies from multiple genes: Concatenated sequence tree versus consensus gene tree. J. Exp. Zool. (Mol. Dev. Evol.) 2005, 304B, 64-74.

56. Ishida, T.; Yokota, A.; Sugiyama, J. Phylogenetic relationships of filamentous cyanobacterial taxa inferred from 16S rRNA sequence divergence. J. Gen. Appl. Microbiol. 1997, 43, 237-241.

57. Wilmotte, A.; Neefs, J.M.; de Wachter, R. Evolutionary affiliation of the marine nitrogen-fixing cyanobacterium Trichodesmium sp. strain NIBB 1067, derived by 16S ribosomal RNA sequence analysis. Microbiology 1994, 140, 2159-2164.

58. Giovannoni, S.J.; Turner, S.; Olsen, G.J.; Barns, S.; Lane, D.J.; Pace, N.R. Evolutionary relationships among cyanobacteria and green chloroplasts. J. Bacteriol. 1988, 170, 3584-3592.

59. Zehr, J.P.; Mellon, M.T.; Hiorns, W.D. Phylogeny of cyanobacterial nifH genes: Evolutionary implications and potential applications to natural assemblages. Microbiology 1997, 143, $1443-1450$. 
60. Valério, E.; Chambel, L.; Paulino, S.; Faria, N.; Pereira, P.; Tenreiro, R. Molecular identification, typing and traceability of cyanobacteria from freshwater reservoirs. Microbiology 2009, 155, 642-656.

61. Gugger, M.F.; Hoffmann, L. Polyphyly of true branching cyanobacteria (Stigonematales). Int. J. Syst. Evol. Microbiol. 2004, 54, 349-357.

62. Rajaniemi, P.; Hrouzek, P.; Kaštovská, K.; Willame, R.; Rantala, A.; Hoffmann, L.; Komárek, J.; Sivonen, K. Phylogenetic and morphological evaluation of the genera Anabaena, Aphanizomenon, Trichormus, and Nostoc (Nostocales, Cyanobacteria). Int. J. Syst. Evol. Microbiol. 2005, 55, 11-26.

63. Thomazeau, S.; Houdan-Fourmont, A.; Couté, A.; Duval, C. The contribution of sub-saharan African strains to the phylogeny of Cyanobacteria: Focusing on the Nostocaceae (Nostocales, Cyanobacteria). J. Phycol. 2010, 46, 564-579.

64. Zapomělová, E.; Skácelová, O.; Pumann, P.; Kopp, R.; Janeček, E. Biogeographically interesting planktonic Nostocales (Cyanobacteria) in the Czech Republic and their polyphasic evaluation resulting in taxonomic revisions of Anabaena bergii Ostenfeld 1908 (Chrysosporum gen. nov.) and A. tenericaulis Nygaard 1949 (Dolichospermum tenericaule comb. nova). Hidrobiologia 2012, 698, 353-365.

65. Neilan, B.A.; Jacobs, D.; Goodman, A.E.; Cox, P.T.; Hawkins, P. Genetic diversity and phylogeny of toxic cyanobacteria determined by DNA polymorphism within the phycocyanin locus. Appl. Environ. Microbiol. 1995, 61, 3875-3583.

66. Wilson, A.E.; Sarnelle, O.; Neilan, B.A.; Salmon, T.P.; Gehringer, M.M.; Hay, M.E. Genetic variation of the bloom-forming Cyanobacterium Microcystis aeruginosa within and among lakes: Implications for harmful algal blooms. Appl. Environ. Microbiol. 2005, 71, 6126-6133.

67. Gaevsky, N.A.; Kolmakov, V.I.; Belykh, O.I.; Tikhonova, I.V.; Joung, Y.; Ahn, T.S.; Nabatova, V.A.; Gladkikh, A.S. Ecological development and genetic diversity of Microcystis aeruginosa from artificial reservoir in Russia. J. Microbiol. 2011, 49, 714-720.

68. El Herry, S.; Nasri, H.; Bouaïcha, N. Morphological and phylogenetic analysis of colonies of Microcystis morphospecies isolated from the Lebna Dam, Tunisia. Afr. J. Microbiol. Res. 2008, 2, 340-348.

69. Fathalli, A.; Jenhania, A.B.R.; Moreira, C.; Welker, M.; Romdhane, M.; Antunes, A.; Vasconcelos, V. Molecular and phylogenetic characterization of potentially toxic cyanobacteria in Tunisian freshwaters. Syst. Appl. Microbiol. 2011, 34, 303-310.

70. Kondo, R.; Kagiya, G.; Hiroishi, S.; Watanabe, M. Genetic typing of a bloom-forming cyanobacterial genus Microcystis in Japan using 16S rRNA gene sequence analysis. Plankton Biol. Ecol. 2000, 47, 1-6.

71. Yoshida, M.; Yoshida, T.; Satomi, M.; Takashima, Y.; Hosoda, N.; Hiroishi, S. Intra-specific phenotypic and genotypic variation in toxic cyanobacterial Microcystis strains. J. Appl. Microbiol. 2008, 105, 407-415.

72. Otsuka, S.; Suda, S.; Li, R.; Watanabe, M.; Oyaizu, H.; Matsumoto, S.; Watanabe, M.M. Phylogenetic relationships between toxic and non-toxic strains of the genus Microcystis based on 16S to 23S internal transcribed spacer sequence. FEMS Microbiol. Lett. 1999, 172, 15-21.

73. Beltran, E.C.; Neilan, B.A. Geographical segregation of the neurotoxin-producing cyanobacterium Anabaena circinalis. Appl. Environ. Microbiol. 2000, 66, 4468-4474. 
74. Stucken, K.; Murillo, A.A.; Soto-Liebe, K.; Fuentes-Valdés, J.J.; Mendéz, M.A.; Vasquéz, M. Toxicity phenotype does not correlate with phylogeny of Cylindrospermopsis raciborskii strains. Syst. Appl. Microbiol. 2009, 32, 37-48.

75. Svenning, M.M.; Eriksson, T.; Rasmussen, U. Phylogeny of symbiotic cyanobacteria within the genus Nostoc based on 16S rDNA sequence analyses. Arch. Microbiol. 2005, 183, 19-26.

76. Wu, Z.; Shi, J.; Lin, S.; Li, R. Unraveling Molecular Diversity and Phylogeny of Aphanizomenon (Nostocales, Cyanobacteria) strains isolated from China. J. Phycol. 2010, 46, 1048-1058.

77. Barker, G.L.A.; Konopka, A.; Handley, B.A.; Hayes, P.K. Genetic variation in Aphanizomenon (Cyanobacteria) colonies from the Baltic Sea and North America. J. Phycol. 2000, 36, 947-950.

78. Fathalli, A.; Jenhani, A.B.; Moreira, C.; Azevedo, J.; Welker, M.; Romdhane, M.; Antunes, A.; Vasconcelos, V. Genetic variability of the invasive cyanobacteria Cylindrospermopsis raciborskii from Bir M'cherga reservoir (Tunisia). Arch. Microbiol. 2011, 193, 595-604.

79. Turner, S.; Pryer, K.M.; Miao, V.P.W.; Palmer, J.D. Investigating deep phylogenetic relationships among cyanobacteria and plastids by small subunit rRNA sequence analysis. J. Eukaryot. Microbiol. 1999, 46, 327-338.

80. Nelissen, B.; van de Peer, Y.; Wilmotte, A.; de Wachter, R. An early origin of plastids within the cyanobacterial divergence is suggested by evolutionary trees based on complete 16S rRNA sequences. Mol. Biol. Evol. 1995, 12, 1166-1173.

81. Rantala, A.; Fewer, D.P.; Hisbergues, M.; Rouhiainen, L.; Vaitomaa, J.; Börner, T.; Sivonen, K. Phylogenetic evidence for the early evolution of microcystin synthesis. Proc. Natl. Acad. Sci. USA 2004, 101, 568-573.

82. Padisák, J. Cylindrospermopsis raciborskii (Woloszynska) Seenayya et Subba Raju, an expanding, highly adaptive cyanobacterium: Worldwide distribution and review of its ecology. Arch. Hydrobiol. Suppl. 1997, 107, 563-593.

83. Neilan, B.A.; Saker, M.L.; Fastner, J.; Torokne, A.; Burnes, B.P. Phylogeography of the invasive cyanobacterium Cylindrospermopsis raciborskii. Mol. Ecol. 2003, 12, 113-140.

84. Gugger, M.; Molica, R.; Le Berre, B.; Dufour, P.; Bernard, C.; Humbert, J.-F. Genetic Diversity of Cylindrospermopsis Strains (Cyanobacteria) Isolated from Four Continents. Appl. Environ. Microbiol. 2005, 71, 1097-1100.

85. Haande, S.; Rohrlack, T.; Ballot, A.; Roberg, K.; Skulberg, R.; Beck, M.; Wiedner, C. Genetic characterization of Cylindrospermopsis raciborskii (Nostocales, Cyanobacteria) isolates from Africa and Europe. Harmful Algae 2008, 7, 692-701.

86. Van Gremberghe, I.; Leliaert, F.; Mergeay, J.; Vanormelingen, P.; van der Gucht, K.; Debeer, A.-E.; Lacerot, G.; de Meester, L.; Vyverman, W. Lack of phylogeographic structure in the freshwater cyanobacterium Microcystis aeruginosa suggests global dispersal. PLoS One 2011, 6, e19561.

87. Cox, C.B.; Moore, P.D. Biogeography: An Ecological and Evolutionary Approach; Blackwell Publishing: Malden, MA, USA, 2005; pp. 1-428.

88. Ramette, A.; Tiedje, J.M. Biogeography: An emerging cornerstone for understanding prokaryotic diversity, ecology, and evolution. Microb. Ecol. 2007, 53, 197-207.

89. Kristiansen, J. Dispersal of freshwater algae — a review. Hydrobiologia 1996, 336, 151-157. 
90. Strunecký, O.; Elster, J.; Komárek, J. Molecular clock evidence fr survival of Antartic cyanobacteria (Oscillatoriales, Phormidium autumnae) from Paleozoic times. FEMS Microbiol. Ecol. 2012, 82, 482-490.

91. Mazard, S.; Ostrowski, M.; Partensky, F.; Scanian, D.J. Multi-locus sequence analysis, taxonomic resolution and biogeography of marine Synechocccus. Environ. Microbiol. 2012, 14, $372-386$.

92. Ahlgren, N.A.; Rocap, G. Diversity and distribution of marine Synechococcus: Multiple gene phylogenies for consensus classification and development of qPCR assays for sensitive measurement of clades in the ocean. Front. Microbiol. 2012, 3, 213.

93. Moreira, C.; Vasconcelos, V.; Antunes, A. Phylogeny of microcystins: Evidence of a biogeographical trend. Curr. Microbiol. 2012, 66, 214-221.

94. Taton, A.; Grubisic, S.; Balthasart, P.; Hodgson, D.A.; Laybourn-Parry, J.; Wilmotte, A. Biogeographical distribution and ecological ranges of benthic cyanobacteria in East Antarctic lakes. FEMS Microbiol. Ecol. 2006, 57, 272-289.

95. Ionescu, D.; Hindiyeh, M.; Malkawi, H.; Oren, A. Biogeography of thermophilic cyanobacteria: Insights from the Zerka Ma'in hot springs (Jordan). FEMS Microbiol. Ecol. 2010, 72, 103-113.

96. Mohamed, Z.A. Toxic cyanobacteria and cyanotoxins in public hot springs in Saudi Arabia. Toxicon 2008, 51, 17-27.

97. Jungblut, A.-D.; Hoeger, S.J.; Mountfort, D.; Hitzfeld, B.C.; Dietrich, D.R.; Neilan, B.A. Characterization of microcystin production in an Antarctic cyanobacterial mat community. Toxicon 2006, 47, 271-278.

98. Vézina, S.; Vincent, W.F. Arctic cyanobacteria and limnological properties of their environment: Bylot Island, Northwest Territories, Canada (731N, 801W). Polar Biol. 1997, 17, 523-534.

99. Zakhia, F.; Jungblut, A.-D.; Taton, A.; Vincent, W.F.; Wilmotte, A. Cyanobacteria in Cold Ecosystems; Springer-Verlag: Berlin, Germany, 2008; pp. 121-135.

100. Garcia-Pichel, F.; Nübel, U.; Muyzer, G. The phylogeny of unicellular, extremely halotolerant cyanobacteria. Arch. Microbiol. 1998, 169, 469-482.

101. Bolch, C.J.S.; Orr, P.T.; Jones, G.J.; Blackburn, S.I. Genetic, morphological and toxicological variation among globally distributed strains of Nodularia (Cyanobacteria). J. Phycol. 1999, 35, 339-355.

102. Hayes, P.K.; Barker, G.L.A. Genetic diversity within Baltic Sea populations of Nodularia (Cyanobacteria). J. Phycol. 1997, 33, 919-923.

103. Garcia-Pichel, F.; Prufert-Bebout, L.; Muyzer, G. Phenotypic and phylogenetic analyses show Microcoleus chthonoplastes to be a cosmopolitan cyanobacterium. Appl. Environ. Microbiol. 1996, 62, 3284-3291.

(C) 2013 by the authors; licensee MDPI, Basel, Switzerland. This article is an open access article distributed under the terms and conditions of the Creative Commons Attribution license (http://creativecommons.org/licenses/by/3.0/). 